\title{
TERAPI AKTIVITAS KELOMPOK (TAK) STIMULASI PERSEPSI DALAM MENURUNKAN TINGKAT KECEMASAN PADA LANSIA
}

\author{
Khamida, Meilisa \\ Fakultas Keperawatan dan Kebidanan \\ Universitas Nahdlatul Ulama Surabaya J1. Smea 57 Surabaya \\ Email: khamida@unusa.ac.id
}

\begin{abstract}
Abstrack : Success elderly people are those who are active, does not work, follow elderly integrated health service (HIS), have healthy lifestyle, , cheerful, and able to maintain their health. The purpose of this study was to determine the effect of Activity Group Therapeutic (AGT) Perception Stimulation on Anxiety Levels at Elderly in Damarsi village Buduran Sidoarjo.Study design is Quasi Experiment with pre-post test control group approach, the population were entire elderly with amount 75 person, some of them 34 respondents taken as sample by simple random sampling method. The independent variable is Activity Group Therapeutic (AGT) Perception Stimulation, the dependent variable is anxiety. Study instrument use questionnaire, observation sheet. Statistical test use Wilcoxon test with a significance level $\alpha=0.05$. The result of the study before the daily routine of 22 respondents are the control group anxiety level was $59,1 \%$, and after the daily routine there is a level of anxiety was $68,2 \%$. While 12 respondents treatment group before (AGT) there is anxiety level was $100 \%$ and after (AGT) are mild anxiety level of $75,0 \%$. Wilcoxon test showed the treatment group $\rho=0,003, \rho<\alpha$ means no influence Activity Group Therapeutic (AGT) Perception Stimulation of the level of anxiety in the elderly in the village Damarsi Buduran Sidoarjo.Elderly anxiety level can be scaled by one of them Activity Group Therapeutic (AGT) Perception Stimulation. Suggestions for the elderly to play an active role in these activities to lower levels of anxiety.
\end{abstract}

Key words : Anxiety, Activity Group Therapeutic (AGT) Perception Stimulation

\begin{abstract}
Abstrak : Lansia di wilayah kerja Posyandu Lansia masih banyak yang bekerja, dan jarang mengikuti kegiatan posyandu lansia.Tujuan dalam penelitian ini adalah untuk mengetahui Pengaruh Terapi Aktivitas Kelompok (TAK) Stimulasi Persepsi Terhadap Tingkat Kecemasan Pada Lansia Di Desa Damarsi Buduran Sidoarjo.Desain penelitian Quasy-Experiment dengan pendekatan pre post test control group design, populasi seluruh lansia cemas sebanyak 75 orang, sampel sebagian lansia sebesar 34 diambil dengan metode simple random sampling. Variabel independen terapi aktivitas kelompok (TAK) stimulasi persepsi, variabel dependen adalah cemas. Instrument yang digunakan adalah lembar kuesioner, lembar observasi.Uji statistik menggunakan uji Wilcoxon dengan nilai kemaknaan $\alpha=$ 0,05.Hasil penelitian sebelum kegiatan rutin harian dari 22 responden kelompok kontrol terdapat tingkat kecemasan sedang 59,1\%, dan setelah kegiatan rutin harian terdapat tingkat kecemasan sedang 68,2\%. Sedangkan 12 responden kelompok perlakuan sebelum (TAK) terdapat tingkat kecemasan sedang 100\% dan setelah (TAK) terdapat tingkat kecemasan ringan $75,0 \%$. Uji Wilcoxon pada kelompok perlakuan menunjukkan $\rho=0,003, \rho<\alpha$ berarti ada pengaruh terapi aktivitas
\end{abstract}


kelompok (TAK) stimulasi persepsi terhadap tingkat kecemasan pada lansia di desa damarsi buduran sidoarjo.Tingkat kecemasan lansia dapat di turunkan dengan salah satunya terapi aktivitas kelompok (TAK) stimulasi persepsi. Saran untuk para lansia untuk berperan aktif pada kegiatan ini untuk menurunkan tingkat kecemasan.

Kata kunci : Kecemasan, terapi aktivitas kelompok (TAK) stimulasi persepsi, lansia

\section{PENDAHULUAN}

Lansia adalah kelompok usia 60 tahun keatas yang rentan terhadap kesehatan fisik dan mental. Penuaan merupakan tahap lanjut dari proses kehidupan yang ditandai dengan penurunan kemampuan tubuh untuk beradaptasi dengan stress lingkungan. Dalam struktur anatomi proses menjadi tua terlihat sebagai kemunduran dalam sel. Proses ini berlangsung secara alami, terus menerus dan berkesinambungan yang selanjutnya akan menyebabkan perubahan anatomi, fisiologis, biokimia dan psikologis. Lansia paling rentang dengan gangguan fisik, dari system pendengaran, penglihatan, respirasi, gastrointestinal, hingga gangguan system lainya. Karena gangguan fisik ini paling banyak membuat lansia menjadi murung, menarik diri dan tidak aktif dalam bersosialisasi.

Lanjut usia yang sukses adalah mereka yang aktif dan mengikuti dalam kegiatan sosial, tidak bekerja, mengikuti posyandu lansia, pola hidup sehat, tidak murung, tidak menyendiri, dan mampu menjaga kesehatanya (Bandiyah Siti, 2009). Di desa Damarsi Buduran Sidoarjo memiliki penduduk $\pm 20 \%$ nya lansia, dimana para lansia tersebut masih banyak yang bekerja, dan jarang mengikuti kegiatan posyandu lansia, para lansia yang bekerja beranggapan mereka harus bekerja karena harus menghidupi dirinya sendiri, mereka merasa keluarganya sudah tidak peduli. Berdasarkan hasil wawancara dengan lansia, lansia menyatakan bahwa banyak lansia hidup dengan keluarga (anaknya) yang sudah berkeluarga, jarang memperhatikannya, dan mereka sering kesepian.

Data dari Badan Pusat Statistik (2010), pertumbuhan jumlah lanjut usia di Indonesia pada tahun 2010 tercatat sebanyak $14.557 .146(9,77 \%)$ jiwa, jumlah lanjut usia di Provinsi Jawa Timur sebanyak 7.956.188 jiwa, jumlah lanjut usia di desa Damarsi yang aktif ke posyandu lansia 30 orang. Data dari penelitian Wahyu wiyono tahun 2010 tentag "Hubungan Antara Tingkat Kecemasan Dengan Kecenderungan Insomnia Pada Lansia Di panti Wredha Dharma Bhakti Surakarta" di dapatkan dari 47 lansia $36 \%$ lansia mengalami kecemasan ringan, $32 \%$ lansia mengalami kecemasan sedang, dan 32\% lansia mengalami kecemasan berat.

Data awal yang dilakukan peneliti pada bulan januari 2014 di Posyandu Lansia Damarsi Buduran Sidoarjo dengan melalui wawancara dan kuesioner tingkat kecemasan kepada 10 lansia, di dapat 7 orang (70\%) dengan melihat cara pandang, gerakan tubuh, tanggapan, serta ekspresi wajah lansia, lansia mengalami tanda-tanda kecemasan dengan keluhan adanya kekhawatiran akan penyakit yang 
dialami, kekhawatiran kondisinya akan bertambah parah, susah tidur, dan merasa tidak berguna sehingga mereka bekerja keras untuk dirinya sendiri dan didukung dengan kuesioner tingkat kecemasan. Selain itu lansia disana sering mengalami gejala fisik seperti sakit pada otot, tulang, dan sakit kepala. Sedangkan 3 orang $(30 \%)$ lansia sangat kooperatif dan santai dalam menjawab pertanyaan yang ajukan. Lansia juga mengatakan tidak merasa terganggu dengan adanya penyakit dalam tubuhnya, dan semua di anggap cobaan tuhan.

Tanda dan gejala kecemasan yaitu bisa karena peristiwa traumatik, konflik antar lansia, tidak percaya diri karena merasa sudah tidak berguna, pola mekanisme koping keluarga yang tidak efektif, menyendiri, pasif, dan gangguan fisik Kecemasan itu sendiri adalah suatu keadaan perasaan kepribadian, rasa gelisah, ketidaktentuan, atau takut dari kenyataan atau persepsi ancaman sumber aktual yang tidak diketahui atau dikenal. Kecemasan yang tidak dapat teratasi dapat memperberat timbulnya penyakit fisik dan gangguan akibat stress. Gambaran klinis cemas biasanya tidak terlihat karena terkadang kecemasan pada orang normal berlangsung dalam intensitas atau durasi yang tidak berkepanjangan sehingga individu dapat tetap memberikan respon yang adaptif (Kusumawati \& Hartono 2012) .

Faktor-faktor yang mempengaruhi cemas pada lansia, yaitu faktor predisposisi (pendukung) dan faktor presipitasi. faktor predisposisi (pendukung) yaitu ketegangan dalam kehidupan dapat berupa hal-hal seperti : peristiwa traumatik, konflik emosional, gangguan konsep diri, frustasi, gangguan fisik, pola mekanisme koping keluarga, riwayat gangguan cemas dan medikasi. Sedangkan faktor presipitasi berupa ancaman kekerasan dan ancaman terhadap harga diri atau penghinaan (farida kusumawati dkk, 2010). Kecemasan apabila tidak di atasi maka lama kelamaan akan membahayakan, karena saat rasa cemas itu datang cara berfikirpun sudah tidak positif, seperti merasa tidak diperhatikan atau dibutuhkan, merasa merepotkan keluarga sehingga ini akan berdampak srius pada psikologinya yang kemudian lama-kelamaan menjadi kecemasan kronis, dimana Kecemasan kronis yaitu menimbulkan potensi depresi serta penyalahgunaan zat dan meningkatkan resiko bunuh diri (Doenges dkk., 2007).

Upaya-upaya yang dilakukan dalam mengatasi kecemasan pada lansia bisa dari faktor keluarga, karena keluarga berperan penting dalam meningkatkan rasa pecaya diri lansia, kemudian faktor lingkungan dan bisa juga dengan terapi aktivitas kelompok (TAK) stimulasi persepsi. Terapi aktivitas kelompok (TAK) stimulasi persepsi adalah terapi yang menggunakan aktivitas sebagai stimulus dan terkait dengan pengalaman dan/atau kehidupan untuk mendiskusikan dalam kelompok yang kemudian hasil diskusi kelompok dapat berupa kesepakatan atau persepsi atau alternative penyelesaian masalah. Yang dilakukan dalam terapi aktivitas kelompok (TAK) stimulasi persepsi yaitu seperti menonton televisi, membaca majalah/Koran, melihat gambar, dan menyanyi. Tujuan umum dari terapi aktivitas kelompok (TAK) stimulasi persepsi agar para lansia mampu untuk menyelesaikan masalah yang diakibatkan oleh paparan stimulus kepadanya. Sedangkan tujuan khusus dari terapi 


\begin{tabular}{|c|c|c|c|c|}
\hline \multirow{2}{*}{$\begin{array}{l}\text { Riwayat } \\
\text { penyakit }\end{array}$} & \multicolumn{2}{|c|}{$\begin{array}{l}\text { Kelompok } \\
\text { perlakuan }\end{array}$} & \multicolumn{2}{|c|}{$\begin{array}{c}\text { Kelompok } \\
\text { kontrol }\end{array}$} \\
\hline & $\mathrm{n}$ & $\%$ & $\mathrm{n}$ & $\%$ \\
\hline Hipertensi & 5 & 41.7 & 13 & 59. \\
\hline \multirow{5}{*}{$\begin{array}{l}\text { Asma } \\
\text { Jantung } \\
\text { Diabetes } \\
\text { Militus } \\
\text { Cholesterol } \\
\text { Asam Urat }\end{array}$} & 1 & 8.3 & 1 & 4.5 \\
\hline & 1 & 8.3 & 0 & 0 \\
\hline & 2 & 16.7 & 2 & 9.1 \\
\hline & 1 & 8.3 & 2 & 9.1 \\
\hline & 2 & 16.7 & 4 & $\begin{array}{c}18 . \\
2\end{array}$ \\
\hline Jumlah & 12 & 100.0 & 22 & $\begin{array}{l}100 \\
.0\end{array}$ \\
\hline \multicolumn{5}{|c|}{$\begin{array}{l}\text { aktivitas kelompok (TAK) stimulasi } \\
\text { persepsi agar lansia mampu } \\
\text { mempersepsikan stimulus yang } \\
\text { dipaparkan kepadanya dengan tepat } \\
\text { dan mampu menyelesaikan masalah } \\
\text { yang timbul dari stimulus yang } \\
\text { dialami (Budi Anna Keliat dkk, 2013). }\end{array}$} \\
\hline
\end{tabular}

\section{METODE}

Desain penelitian ini menggunakan penelitian Quasy-Experiment dengan pendekatan pre post test control group design, populasi seluruh lansia cemas sebanyak 75 orang, sampel sebagian lansia sebesar 34 diambil dengan metode simple random sampling. Variabel independen terapi aktivitas kelompok (TAK) stimulasi persepsi, variabel dependen adalah cemas. Instrument yang digunakan adalah lembar kuesioner, lembar observasi.Uji statistik menggunakan uji Wilcoxon dengan nilai kemaknaan $\alpha=0,05$.

\section{HASIL \& PEMBAHASAN}

\section{a. Hasil}

1. Data Umum

Distribusi responden berdasarkan riwayat penyakit

Tabel 1. Distribusi frekuensi responden berdas-arkan riwayat penyakit pada kelompok perlakuan dan kelompok kontrol terapi aktivitas kelompok stimulasi persepsi.

Sumber: Data Primer Juni 2015

\section{Data Khusus}

Tabel 1. Distribusi pada kelompok perlakuan dan kelompok kontrol sebelum dan sesudah diberikan terapi aktivitas kelompok (TAK) stimulasi persepsi

\begin{tabular}{lccccccccc}
\hline \multirow{2}{*}{ Tingkat } & \multicolumn{3}{c}{ Kelompok perlakuan } & \multicolumn{3}{c}{ Kelompok kontrol } \\
\cline { 2 - 10 } Kecemasan & \multicolumn{2}{c}{ Pre } & \multicolumn{2}{c}{ Post } & \multicolumn{2}{c}{ Pre } & \multicolumn{2}{c}{ Post } \\
& $\mathrm{n}$ & $\%$ & $\mathrm{n}$ & $\%$ & $\mathrm{n}$ & $\%$ & $\mathrm{n}$ & $\%$ \\
\hline Normal & 0 & 0 & 0 & 0 & 0 & 0 & 0 & 0 \\
Ringan & 0 & 0 & 9 & 75 & 9 & 40,9 & 7 & 31,8 \\
& & & & & & & & \\
Sedang & 12 & 100 & 3 & 25 & 13 & 59,1 & 15 & 68,2 \\
Berat/panik & 0 & 0 & 0 & 0 & 0 & 0 & 0 & 0 \\
\hline Jumlah & 12 & 100 & 12 & 100 & 22 & 100 & 22 & 100 \\
\hline Wilcoxon & \multicolumn{3}{c}{$0,003 *$} \\
\hline Sumber:
\end{tabular}

Sumber: Data Primer Juni 2015

\section{b. Pembahasan}

Hasil penelitian pada tabel 2 menunjukkan bahwa pada kelompok kontrol sebelum diberikan kegiatan rutin harian didapatkan dari 22 responden sebagian besar $(59,1 \%)$ mengalami tingkat kecemasan sedang. Secara keseluruhan lansia mengeluh seperti mudah marah, panik, pusing, gangguan pencernaan, nyeri kepala dan punggung, kemudian sering buang air kecil dan juga tidak dapat beristirahat atau tidur malam dengan baik, ini adalah tanda dari kecemasan. Menurut seorang ahli (dalam Nugroho, 2008), mengatakan bahwa perubahan yang terjadi pada seseorang lanjut usia sangat dipengaruhi oleh tipe personalitas yang dimilikinya.

Pada tabel 2 juga menunjukkan bahwa pada kelompok perlakuan sebelum diberikan terapi aktivitas kelompok (TAK) stimulasi persepsi 
didapatkan dari 12 responden seluruhnya (100\%) mengalami tingkat kecemasan sedang. Lansia yang mengalami tingkat kecemasan ringan, sedang maupun berat dapat masuk dalam kategori berbahaya karena saat lansia mengalami kecemasan lansia akan menarik diri dari lingkungan sosial dan lingkungan keluarga ini akan menyebabkan resiko depresi. Menurut teori yang pertama ditujukan oleh Cumming dan Henry (dalam Nugroho, 2009), mengatakan bahwa dengan bertambahnya lanjut usia, apalagi ditambah dengan adanya kemiskinan, lanjut usia secara berangsur angsur mulai melepas diri dari kehidupan sosialnya atau menarik diri dari pergaulan sekitarnya. Keadaan ini mengakibatkan interaksi sosial lanjut usia menurun, baik secara kualitas maupun kuantitas sehingga sering lanjut usia mengalami kehilangan ganda (triple loss), kehiangan peran (loss of role), hambatan kontak sosial (restriction of contact and relationship), berkurangnya komitmen (reduced commitment to social mores and values).

Lansia setelah diberikan terapi aktivitas kelompok (TAK) stimulasi persepsi mengalami perubahan tingkat kecemasan berdasarkan tabel 2 menunjukkan bahwa pada kelompok kontrol sesudah diberikan kegiatan harian didapatkan dari 22 responden sebagian besar $(68,2 \%)$ memiliki tingkat kecemasan sedang. Secara keseluruhan tingkat kecemasan lansia mengalami peningkatan dengan tandatanda lansia mudah marah dan panik karena penyakit yang dideritanya, terganggu oleh nyeri kepala leher dan nyeri punggung, terganggu oleh nyeri lambung atau gangguan pencernaan, pusing, lansia juga sering buang air kecil, dan hanya sebagian lansia dapat tidur dengan baik. Untuk mempertahankan kualitas hidup yang baik, seseorang harus selalu berusaha memelihara kesehatan dengan baik dan teratur agar tidak mudah dihinggapi penyakit dan agar kemunduran faali berbagai organ tubuh dapat diketahui sedini mungkin (Maryam, 2008).

Berdasarkan tabel 2 menunjukkan bahwa pada kelompok perlakuan sesudah diberikan terapi aktivitas kelompok (TAK) stimulasi persepsi didapatkan dari 12 responden sebagian besar $(75,0 \%)$ memiliki tingkat kecemasan ringan. Pada terapi aktivitas kelompok sesi 1 yaitu stimulasi adaptasi perubahan aspek biologi. Lansia berkumpul kemudian mengisi lembar kuesioner tingkat kecemasan dan setelah itu kegiatan TAK dimulai. Tujuan dari sesi 1 yaitu lansia dapat mengenal perubahanperubahan alamiah aspek biologi pada diri lansia. Lansia juga dapat meyampaikan pendapatnya tentang perubahan biologi yang terjadi pada dirinya dan upaya-upaya yang dapat dilakukan agar tetap bugar dan sehat. Selama sesi lansia mengikuti jalanya acara dengan baik, saat ada pertanyaan lansia menjawab, dan tidak ada lansia yang meninggalkan ruangan. Pada sesi 2 stimulasi adaptasi perubahan aspek psikologis (kognitif) bertujuan lansia dapat mengidentifikasi cara-cara adaptasi dengan perubahan kognitif untuk mencegah kepikunan diusia lansia. Lansia mengikuti permainan yang diajukan panitian, dan mereka mampu menyelesaikan permainannya dengan benar. Pada sesi 3 stimulasi adaptasi perubahan aspek kognitif (emosional), bertujuan mengidentifikasi pikiran negative terhadap diri sendiri, orang lain atau lingkungan. Secara keseluruhan lansia berfikir negative terhadap dirinya 
sendiri, merasa membebani orang lain, mengusik kenyamanan orang lain, dan merasa tidak berguna bagi keluarga dan lingkunganya.

Sesi 4 yaitu stimulasi adaptasi perubahan aspek sosial tujuan dari terapi ini untuk mengidentifikasi aspek positif yang ada didalam diri untuk menjalin hubungan dengan keluarga dan masyarakat. Lansia menjawab kebanyakan yang membuat lansia tidak percaya diri dirumah karena tidak dapat membantu anak-anaknya bekerja dan mengurus pekerjaan rumah dengan benar, kemudian ada pula lasia yang menjawab lansia masih bertani walau sebenarnya tubuhnya sudah tidak mampu tapi demi kehidupanya sehari-hari karena tidak mau membebani anak-anaknya yang sudah berumah tangga, kemudian ada juga yang menjawab karena penyakitnya yang tidak kunjung sembuh, seperti pega-pegal, asam urat, cholesterol, diabetes militus, pusing dan jantung. Sesi 5 yaitu stimulasi adaptasi perubahan aspek spiritual. Tujuan terapi ini untuk mengidentifikasi keyakinan spiritual yang memenuhi kebutuhan untuk memperoleh arti dan tujuan hidup, mencintai, keterikatan dan pengampunan dari tuhan. Lansia keseluruhan menjawab tujuan hidup didunia itu hanya mencari amal sebanyak-banyaknya dan meminta ampun kepada Allah untuk mencari kedamaian diakhirat kelak. Sesi 6 stimulasi adaptasi perubahan aspek integritas diri. Tujuan dari sesi 6 yaitu lansia mampu menyampaikan perubahan-perubahan pada dirinya dari aspek 1 sampai dengan 5. lansia mampu melewati setiap sesi dari TAK. Lansia juga sudah mampu menstimulus dirinya sendiri untuk berfikir positif agar dapat memecahkan masalahnya sendiri tanpa lari lagi. Lansia juga mampu bersosialisasi dengan bagus tanpa berfikir kekurangan yang ada pada dirinya. Lansia mengatakan ini pengalaman pertama mereka sehingga ini sesuatu yang baru dan bagus untuk para lansia, karena disini suara mereka dapat didengar, dan karena disini mereka merasa sangat diperhatikan. Setelah TAK lansia diberi kuesioner tingkat kecemasan.

Secara keseluruhan lansia mengalami penurunan tingkat kecemasan yang awalnya mudah marah dan panik, merasa lengan dan kakinya gemetar, terganggu oleh nyeri kepala leher dan nyeri punggung dan terganggu oleh nyeri lambung dan gangguan pencernaan sekarang sedikit-sedikit lansia dapat menerima dan mengatasinya, kemudian lansia juga dapat berinteraksi dengan lansia lainya maupun dengan mahasiswa. Menurut seorang ahli (dalam Darmojo, 2009), mengatakan bahwa lanjut usia yang sukses adalah mereka yang aktif dan banyak ikut serta dalam kegiatan sosial. Lansia akan merasakan kepuasan bila dapat melakukan aktivitas dan mempertahankan aktivitas tersebut selama mungkin.

Pada kelompok perlakuan sesudah (post) diberikan TAK Stimulasi persepsi didapatkan dari 12 responden sebagian besar $(75,0 \%)$ ada selisih skor $=9$, sedangkan kelompok kontrol (post) dari 22 responden sebagian besar $(68,2 \%)$ ada selisih skor $=8$ pada penilaian zung self-rating anxiety scale (SAS/SRAS). Berdasarkan uji Wilcoxon Sign Rank pada kelompok perlakuan di dapatkan nilai $\mathrm{P}=0,003$ dan nilai $\alpha=0,05$ berarti $\mathrm{P}<\alpha$ maka Ho ditolak, artinya ada pengaruh terapi aktivitas kelompok (TAK) 
stimulasi persepsi terhadap tingkat kecemasan lansia di posyandu lansia desa damarsi buduran sidoarjo. Sedangkan kelompok kontrol didapatkan nilai $\mathrm{P}=0,157$ dan nilai $\alpha$ $=0,05$ berarti $\mathrm{P}>\alpha$ maka $\mathrm{H} 0$ diterima, yang berarti tidak ada pengaruh pada tingkat kecemasan lansi pada kelompok kontrol karena tidak diberikan terapi aktivitas kelompok (TAK) stimulasi persepsi. Hal ini sesuai dengan teori keliat (2013) yaitu terapi aktivitas kelompok (TAK) stimulasi persepsi merupakan salah satu faktor yang mempengaruhi tingkat kecemasan.

\section{KESIMPULAN}

Berdasarkan hasil penelitian tentang Pengaruh Terapi Aktivitas Kelompok (TAK) Stimulasi Persepsi Terhadap Tingkat Kecemasan Pada Lansia Di Desa Damarsi Buduran Sidoarjo dapat disimpulkan bahwa: Ada Pengaruh terapi aktivitas kelompok (TAK) stimulasi persepsi terhadap tingkat kecemasan pada lansia di Posyandu Lansia Desa Damarsi Buduran Sidoarjo.

\section{Saran}

Kecemasan pada lansia dapat dicegah dengan pendekatan kepada masyarakat untuk mempromosikan cara hidup sehat pada semua lansia beserta orang terdekat atau keluarganya.

\section{DAFTAR PUSTAKA}

Azizah, M (2011). Keperawatan lanjut Usia. Yogyakarta :Grahallmu.

Azizah, M (2013). Pengaruh Komunikasi Terapeutik Terhadap Kecemasan Lansia yang Tinggal Di Balai Rehabilitasi Sosial "Mandiri" Pucang Gading Semarang .www.Wordpress.com, diunduh pada tanggal 28 maret 2015 pukul 11:55 WIB.

Bandiyah, Siti. (2009). Lanjut Usia dan Keperawatan Gerontik. Yogyakarta, Medical Book.

Darmojo. (2006). Geriatri. Jakarta : yudistira

Depkes RI. (2005). Batasan Umur Pada Lansia.Jakarta :Salemba Medika.

Keliat, B.A (1999). Komunikasi Efektif dalam Keperawatan.Jakarta : EGC.

Kusumawati, Farida \& Hartono, yudi. (2012). Buku Ajar Keperawatan Jiwa.Jakarta: Salemba Medika

Listiana, Dahrianis, $\operatorname{dkk}(2013)$. Hubungan Antara Berpikir Positif Terhadap Kecemasan Lansia Di Panti Tresna Werda Kabupaten Gowa. Diunduh pada tanggal 29 maret 2015 pukul 12:08

Machfoedz, M. (2009). Komunikasi Keperawatan : Komunikasi Terapeutik. Yogyakarta : Ganbika.

Maryam R, S, dkk (2011). Mengenal Usia lanjut dan Perawatannya. Jakarta : Salemba Medika.

Maryam, Ekasari, Rosidawati, dkk. (2008). Mengenal Usia Lanjut dan Perawatannya. Jakarta :Salemba Medika.

Musliha \& Fatmawati, S. (2010). Komunikasi Keperawatan : Plus Materi Komunikasi terapeutik. Yogyakarta : Nuha medika. 
Noorkasiani, S. T (2009). Kesehatan usia lanjut dengan pendekatan asuhan keperawatn. Jakarta : Salemba medika.

Nugroho, W. (2008). Keperawatan Gerontik dan Getriatrik. Jakarta : EGC.

Nugroho, wahjudi. (2008). Keperawatan Gerontik\&Geriatrik (edisi 3). Jakarta : EGC.

Nursalam.(2013). Metodologi Penelitian Ilmu Keperawatan edisi. Jakarta :Salemba Medika

Stevan(2005). Panduan gerontology. Jakarta : EGC.

Stuart, Gail. W. (2007). Buku Saku Keperawatan Jiwa. Edisi 5.Jakarta : ECG.

Videbeck L, Sheila. (2008). Buku Ajar Keperawatan Jiwa, edisi1.Jakarta : EGC.

Wiyono, Wahyu. (2009). Hubungan Antara Tingkat Kecemasan Dengan Kecenderungan Insomnia pada Lansia Di Panti Wherda Bakti. Fakultas Ilmu Kesehatan Universitas Muhammadiyah Surakarta. Surakarta. Diunduh pada tanggal 9 Februari 2015 pada pukul 11.30 